\title{
Global perspectives and case studies of environmental management and policy
}

\author{
Zachary A. Collier ${ }^{1} \cdot$ James H. Lambert $^{1} \cdot$ Igor Linkov $^{2}$
}

Published online: 30 October 2017

(C) Springer Science+Business Media, LLC 2017

The December issue of Environment Systems and Decisions features applied research and demonstrations related to environmental management and environmental policy. These articles feature worldwide perspectives and case studies from multiple continents and highlight broader implications for environmental issues on a global scale. Topics such as climate adaptation, pollution reduction, health risk assessment, and sustainable product development are investigated with a variety of circumstances with individuals, industry, government, and the military.

We open the issue with a special paper by Roland W. Scholz, a member of the Editorial Board of Environment Systems and Decisions, providing a discussion of the contributions of Egon Brunswik's Theory of Probabilistic Functionalism (Scholz 2017). The paper explores fascinating implications of the theory to group and organizational decision making and planning. For this paper, we implemented a novel participatory peer review process, in which we received approximately 10 peer reviews, and offered the reviewers an opportunity to submit short response articles. So far we have received seven response articles, with more anticipated.

The Editorial Board invites additional responses to this paper, to be published in the subsequent issue of

Zachary A. Collier

zac4nf@virginia.edu

James H. Lambert

Lambert@virginia.edu

Igor Linkov

Igor.Linkov@usace.army.mil

1 University of Virginia, Charlottesville, VA, USA

2 US Army Engineer Research and Development Center, Concord, MA, USA
Environment Systems and Decisions. The responses are encouraged from a wide diversity of disciplines and perspectives, including but not limited to: psychology, decision theory, environmental sciences, policy and planning, philosophy, and others. Topics may include, but are not limited to:

- How meaningful and important is Brunswik's approach today?

- Has Brunswik's approach been helpful for some of the theoretical questions that are encountered with humanenvironment interactions?

- How viable is the proposed upscaling of Brunswik's approach from an organism's perception to higher ordered human systems?

- The Scholz paper stresses (and obviously shares) Brunswik's view that there is a strong coupling between the (objective) environmental stimuli and the functionality of the cues that are perceived. How is this aligned with an evolutionary perspective? What aspects are important subject to changing world conditions?

- What status does Brunswik's approach have in each of various disciplines?

- What else is noteworthy from the perspective of the Springer journal Environment Systems and Decisionsdecision making, risk analysis, systems engineering, risk communication, resilience analysis, etc.?

The response papers will be reviewed by Dr. Scholz, and published in the March issue, along with an integrated summary article addressing the collected responses. We are excited to publish the results from this innovative peer review process.

The remainder of this issue opens with an article describing structured expert elicitation of judgments on ecosystembased adaptation under multiple climate scenarios (Procter 
et al. 2017). This is demonstrated in a case study on a watershed management plan in Honduras. Turki et al. (2017) investigate the environmental management systems within the food industry of Tunisia, addressing multiple environmental performance indicators in compliance with international standards. Next, a cloud-based decision support system for health risk assessment is described (Singh 2017). The decision support system is demonstrated by assessing cancer risks arising from arsenic consumption. Azmi and Tokai (2017) implement a systems dynamics modeling approach to study the effects of government policy alternatives and changing populations in Malaysia on the national ownership of electric vehicles. Malsch et al. (2017) describe how user perspectives and mental models can inform the development of decision support systems. The authors describe how multiple industry, regulatory, and other user perspectives are assessed and integrated into a decision support system for nanotechnology-enabled products.

The Editorial Board would like to remind that the following special issues are forthcoming, and articles are still welcome, regarding (1) resilience and (2) emerging technologies.

Finally, the Editorial Board will soon select the winner from among the finalists for the ESD Best Paper Award, in cooperation with the Society for Risk Analysis (SRA) Decision Analysis and Risk Specialty Group (DARSG). The nominees have been selected from the submitted abstracts of the upcoming SRA Annual Meeting, held in December. The authors of the ESD Best Paper Award will share \$500, and all finalists will be eligible for publication in an upcoming issue of Environment Systems and Decisions.

\section{References}

Azmi M, Tokai A (2017) Electric vehicle and end-of-life vehicle estimation in Malaysia 2040. Environ Syst Decis. https://doi. org/10.1007/s10669-017-9647-4

Malsch I, Subramanian V, Semenzin E, Zabeo A, Hristozov D, Mullins M, Murphy F, Linkov I, Marcomini A (2017) Comparing mental models of prospective users of the sustainable nanotechnology decision support system. Environ Syst Decis. https://doi. org/10.1007/s10669-017-9648-3

Procter A, McDaniels T, Vignola R (2017) Using expert judgments to inform economic evaluation of ecosystem-based adaptation decisions: watershed management for enhancing water supply for Tegucigalpa, Honduras. Environ Syst Decis. https://doi. org/10.1007/s10669-017-9645-6

Scholz RW (2017) Managing complexity: from visual perception to sustainable transitions-contributions of Brunswik's theory of probabilistic functionalism. Environ Syst Decis. https://doi. org/10.1007/s10669-017-9655-4

Singh SK (2017) Conceptual framework of a cloud-based decision support system for arsenic health risk assessment. Environ Syst Decis. https://doi.org/10.1007/s10669-017-9641-x

Turki M, Medhioub E, Kallel M (2017) Evaluation of a national food industry based on environmental performance and condition indicators: critical success and barriers of EMS implementation in Tunisia. Environ Syst Decis. https://doi.org/10.1007/ s10669-017-9646-5 